\title{
Jinn and Mental Illness among Muslims - A Commentary
}

\author{
Md Rosli $A N^{a}$, Hashi $A A^{b}$, Razali $Z A^{c}$ \\ aDepartment of Psychiatry, Kulliyyah of Medicine, International Islamic University Malaysia (IIUM). \\ ${ }^{\mathrm{b}}$ Center for Islamization (CENTRIS), International Islamic University Malaysia (IIUM). \\ 'Universiti Sains Islam Malaysia (USIM)
}

\section{ABSTRACT}

It is common for Muslims to associate mental illness with the work of jinn. Typically, an initial consultation with folk-healer is made within the local community by those who experience deviant symptoms. This behaviour results in several serious negative health implications. Misconception about the meaning of Islamic medicine, the use of ruqyah among the public, and the lack of culturally competent approach in handling mental illnesses are thought to perpetuate the problem. Despite the lack of evidence in the Qur'an and Sunnah to support jinn possession, the belief persists in the community. Thus, a multidisciplinary approach through engagement, advocacy, and research are much needed to manage the issue at hand.

KEYWORDS: Jinn, Mental Health, Muslim, Culture, Islam

How serious is the problem?

The attribution of mental illness to a supernatural cause is prevalent but not unique to Muslim communities. The local Malay Muslim population identifies various psychological symptoms with different cultural labels, aetiology, and treatment; i.e. "meroyan" and post-partum psychosis. ${ }^{1}$ and "histeria" with various forms of psychiatric diagnoses from anxiety disorders to conversion disorder and schizophrenia. $^{2}$

Complex unexplainable symptoms that occur in a patient will be formulated within his own local support system and explained away through the notion of supernatural causation. Social and selfstigma prevent them from getting the help needed. In this way, consultation with mental health professionals is often made only as a last resort after treatment by spiritual healers has failed. ${ }^{3}$

Malaysia has limited studies to illustrate the problem at hand. A cross-sectional study found, of those who

Corresponding author:

Asst. Prof. Dr. Ahmad Nabil Md Rosli

Department of Psychiatry,

Kulliyyah of Medicine,

International Islamic University Malaysia (IIUM).

Jalan Sultan Ahmad Shah,

Bandar Indera Mahkota,

25200 Kuantan, Pahang, Malaysia

Tel No : +609-5706211

Email : ahmadnabil@iium.edu.my attended a Muslim spiritual healing centre, 53.3\% attendees were diagnosable with at least one psychiatric diagnosis, e.g. depression (41.5\%), anxiety disorder (28.3\%), bipolar disorder (16.8\%), and psychotic disorder (5.9\%). ${ }^{4}$ While this helpseeking is mostly done on a voluntary basis, it has some implications.

Healers who have a constricted notion of the aetiology of psychiatric diagnoses i.e. caused by jinn, ${ }^{5}$ may delay patients from seeking professional help from the mental health fraternity and reinforce the stigma. While another local study on patients with schizophrenia has proven this hypothesis to be wrong, ${ }^{6}$ it could not be generalised to other milder psychiatric conditions such as depression and neurosis. ${ }^{6}$ Muslim patients with religious obsessivecompulsive disorder are known to present late to mental health providers. In addition, spiritual healers who practice spiritual healing are not bound by law that governs their practice and thus may pose danger to patient safety by means of potential abuse. ${ }^{6}$

\section{What are the factors that perpetuate the problem?}

The factors can be reduced into two categories; public and mental health professionals. There is disorientation in the public sphere over the usage and meaning of certain terminologies, i.e. Islamic Medicine and Islamic Medical Practitioners. These terms are used by certain parties in a limited purview that may confuse the public into discrediting 
conventional treatment as un-Islamic. ${ }^{8}$ Overspiritualisation; the obsession of attributing illness to supernatural causes, has reduced the treatment to spiritual remedies, e.g. ruqyah. This attitude causes more harm than good, affecting one's health or the one who is cared for. From the perspective of doctrinal knowledge, Malaysian Muslims tend to have an incorrect view of the role and utilisation of ruqyah. It is understood in a narrow perspective as if ruqyah requires training by 'certified' individuals, ruqyah is only for spiritual illness, and ruqyah is used for diagnosing illness. ${ }^{2}$

Another factor that perpetuates the problem is the inadequacy of a culturally competent approach to mental health problems in our local culture. For any intervention to be deemed effective, it must not only be categorised as evidence-based but also demands cultural competency as defined by "a set of congruent behaviours, attitudes, skills, policies and procedures that enable the organisation's caregivers to work effectively and efficiently in cross / multicultural situations." 9 Cultural competence allows for the integration of religion/spirituality in the illness formulation and treatment plan, and reduces prejudice and judgement at both ends. To say the least, many medical practitioners are not well equipped with the knowledge and skills required to handle sensitive issues related to religion and culture.

\section{What does the Quran say about Jinn and human} beings?

The apparent preoccupation of Muslims with the supernatural cause to mental illness is thought to have its roots in the Muslim religious scripture. Among the subjects addressed in the Qur'an is the existence of jinn; a creation which shares certain similar characteristics to man (insan), but different traits in other aspects. The following points are eight (8) relevant facts about jinn in relation to human being:

From the Islamic theological perspective, (i) jinn is considered a mortal being made of fire, contrary to angels and man, which are made of light and dust respectively. (ii) Like man, jinn is created as a being imbued with moral responsibility, with its own raison d'être; the realisation of divine power through the submission to God's order. (iii) Following this, jinn is given the freedom to choose between good or bad, i.e. angelic or evil acts, and thus between belief or disbelief in God. (iv) It is the latter category of jinn (and man) that have wilfully deviated from the right path and disobeyed the Divine Commands of God, due to arrogance (istakbara) and logical fallacy. (v) They employ all measures to deceive decent and good individuals, and thus lead them astray. However, it is important to note that the deception is weak and feeble, and cannot resist the power of reason, will and the Divine Guidance given to any man. Unless these powers are not utilised, the evil tricks and whisperings cannot influence the faculties of man. (vi) The evil ones among jinn and Mankind, can offer evil tricks and suggestions that assail the mind (nazagha) by means of illusion, i.e. presenting evil things as beautiful (zayan lahum al-shaytan), but not to the extent of possession. (vii) The Qur'an records an insightful debate yet to come on the Day of Judgement, where it portrays the powerlessness of Satan to 'possess' man. (viii) Perhaps, its limited influence upon mankind will be of effect only if the individual seeks its patronage. The contrary is true for those who seek refuge from Almighty God. The above points are summarised in table 1 .

\section{The way forward}

Despite the fact that the belief in jinn possession is not clearly stated or found in the divine sources (the Qur'an and Sunnah) of Islamic teachings, the belief and practice remain. Thus, the approach to this problem should be multi-prong through engagement, advocacy, and research.

As a matter of fact, there has been more engagement than ever before; by the mental health professionals, religious scholars, and spiritual healers, in public and academic forums regarding this issue. Public forums are continuously organised by institutions such as International Islamic University Malaysia (IWIN16: Islam and Psychiatry) and Universiti Sains Islam Malaysia (Ruqyah dalam Pengamalan Perubatan Kontemporari 2017), to cite a few.

Religious scholars should come forward to clear the misconception in the public domain to reduce the stigma of those who have mental illnesses. Where a unanimous decision cannot be reached, all parties must come to agreement that the effort must be directed towards the principle of Maqasid alShariyyah; preserving health (biopsychosocialspiritual) and prevention of harm to patients. An 
Table 1: Summary of the important characteristics of jinn in relation to human beings with its Quranic reference

\begin{tabular}{|c|c|c|}
\hline No & Description & $\begin{array}{l}\text { Quranic reference } \\
\text { (Name of Chapter-Surah:Ayah) }\end{array}$ \\
\hline 1 & Jinn is God's mortal being created from fire & $\begin{array}{l}\text { Sad -38:76 } \\
\text { Al-A'raf -7: } 12-18\end{array}$ \\
\hline 2 & $\begin{array}{l}\text { Jinn is a moral agent (imbued with moral } \\
\text { responsibility) }\end{array}$ & $\begin{array}{l}\text { Adh-Dhariyat }-51: 56 \\
\text { Ar-Rahman }-55: 31\end{array}$ \\
\hline 3 & Jinn has free will to choose right and wrong & Al-Jinn -72:11-16 \\
\hline 4 & Devilish act: Jinn and Man & $\begin{array}{l}\text { Al-An'am -6:112 } \\
\text { Sad 38:-74-76 }\end{array}$ \\
\hline 5 & Weakness of Jinn's trickery & $\begin{array}{l}\text { Al-A'raf }-7: 11-18 \\
\text { An-Nisa }-4: 76\end{array}$ \\
\hline 6 & Evil suggestion, not possession & $\begin{array}{l}\text { Al-A'raf }-7: 200 \\
\text { An-Nas }-114: 4-5\end{array}$ \\
\hline 7 & No authority to possess & $\begin{array}{l}\text { Ibrahim -14:22; } \\
\text { Qaf -50:27-29 }\end{array}$ \\
\hline 8 & No effect for those who seek God's refuge & An-Nahl -16:99-100 \\
\hline
\end{tabular}

initiative by the Mental Illness Awareness and Support Association (MIASA) should be applauded. It forms a collaborative assessment team involving psychiatrists and spiritual healers in a non-hospital setting, aspires to set methodological differences aside and to bring benefits to patients with psychological disorders. Establishment of spiritual care services (clinical chaplaincy) in clinical settings; inpatient or outpatient, which attend to religious and spiritual issues, may bring the gap closer.

Ideally, the subject of cultural competence in medical practice should be taught during the undergraduate medical study which, to our knowledge, is still lacking in the local context. At the level of master's degree, e.g. psychiatry, important subjects like practical cultural psychiatry should be given more weightage, focusing on practical aspects of patient's formulation, i.e. identification of the illness explanatory model, idioms of distress, cultural formulation interview, etc.

A growing body of research and publication has also been put forward by local researchers. Recently, a book entitled "Medical Wisdom and Ar-Ruqyah AshShar'iyyah" was written as an academic response to the issue at hand. ${ }^{2}$ Razali and Tahir (2018), reiterate the importance of understanding 'Islamic medicine' properly and holistically. ${ }^{8}$ Any treatment which is proven effective, safe, and in keeping with Maqasid al-Shariyyah in treating a disorder or disease is deemed Islamic.

The authors emphasise that an integrated bio-psycho -socio-spiritual approach is the only way forward, in which Muslim doctors need to be very well-equipped with spiritual endowment and psycho-spiritual skills to treat patients holistically. With sound basic medical background, holistic Muslim doctors are the frontline in caring for psychiatric illnesses, and hence the need for so-called 'Islamic Medical Practitioners' (Pengamal Pengubatan Islam) is redundant. The public should be educated on the principles of medicine that are in line with the Maqasid al-Shariyyah and to encourage them to see that without the 'Islamic' labelling, effective modern medicine is Islamic indeed.

\section{Conflict of Interest None}

\section{Acknowledgement}

None 


\section{REFERENCES}

1. A Ab Razak A. Cultural construction of psychiatric illness in Malaysia. The Malaysian journal of medical sciences: MJMS 2017; 24:1.

2. Shaharom MH, Razali ZA, eds. Medical Wisdom and Ar-Ruqyah Ash-Shar'iyyah. Selangor: Universiti Islam Malaysia, 2018

3. Shoesmith WD, Borhanuddin AF, Yong Pau Lin P, Abdullah AF, Nordin N, Giridharan B, Forman D, Fyfe $S$. Reactions to symptoms of mental disorder and help seeking in Sabah, Malaysia. International Journal of Social Psychiatry 2018; 64:49-55

4. Abdullah KH, Saini SM, Sharip S, Shaharom MH. Psychiatric Morbidities among Attenders of an Islamic Spiritual Healing Centre in Malaysia. International Medical Journal Malaysia 2017; 1:16.

5. Md. Sa'ad RA, Razali ZA, Sanip S, Mohd Rani MD. Knowledge and attitude of Malaysia's Muslim faith healers in dealing with the mentally ill. Mental Health, Religion \& Culture 2017; 20:101527.

6. Phang CK, Midin M, Aziz SA. Traditional healers are causing treatment delay among patients with psychosis in Hospital Kuala Lumpur: Fact or fallacy?. ASEAN Journal of Psychiatry 2010; 11:206-15

7. Razali ZA, Tahir MF. The Role of Psychiatrists and Muslim Faith Healers in Mental Health Issues. International Medical Journal Malaysia 2018; 2:17

8. Bhui K, Warfa N, Edonya P, McKenzie K, Bhugra D. Cultural competence in mental health care: a review of model evaluations. BMC health services research 2007; 7:15 